Journal of Education and Vocational Research

Vol. 1, No. 1, pp. 1-3, Apr 2011

Book Review

The Leadership Challenge

\author{
Author: Barry Z. Posner, James M. Kouzes \\ Review by: Varsha Dixit \\ School of Management, Gautam Buddha University, India \\ varshadixit2003@gmail.com
}

\title{
1. The Leadership Challenge
}

Leadership is a value loaded term. The earlier notions credited leaders with supernatural powers. In recent times, leadership has a rational explanation. It is identified as a social -influence process. Business organizations require leaders at every level to sustain their growth and be ahead of competitors. The leaders must have value -driven personalities who can control circumstances, make things happen, win employee's commitment, develop better environment and work culture and lead the organization.

The book 'The Leadership Challenge' is research and evidence based which assists the managers and individual contributors in developing their abilities to lead others to get extraordinary things done. The book focuses on how ordinary people can become excellent leaders. The companies must focus on their employees and mange the rapidly changing workforce. Successful leaders posses certain distinguishing qualities like intelligence, emotional balance, technical skills, communication skills, inner drive, high energy level and human relations skills. Leaders must be competent, honest, broad and fair minded, straightforward, determined, independent etc. They are the ones who deliver what they say and lead from the front. According to Kouzes and Posner, "There exists transformed relationship between the customers and the employees of the organization" (pg. 5). Another important feature is communication needed to deliver and receive information from the people.

Leaders help the team to focus on creativity than just manufacturing mentality. In the words of Alan 'Creative people by nature want some sense of leadership' (Kouzes \& Posner, 2007; pg. 10). The leaders have deep connections with their followers to create trustworthy system. Leadership challenge is mainly focused on getting extraordinary things done in organizations and includes five practices of exemplary leadership (Kouzes and Posner, page 68) The first practice Model the way says do not ask anyone to do anything which you are unwilling to do first" (Kouzes \& Posner; pg. 14). This principle is beneficial as it helps the leaders to be straightforward and also communicate to the people as to what they aim for and what they believe. It also helps in creating transparency and defines the roles of the followers working under a leader. The leaders should stand up for their belief and also guide the way for the people to follow the values set. Shared values are the foundations for building productive and genuine working relationships (Kouzes and Posner, page 60)

The second principle shown by the authors is to inspire a shared vision. When leader shares a vision it enables people to realize their dreams and also become confident to do extraordinary things. It helps to rejuvenate and reenergize a decaying organizational culture. The leaders should constitute a destiny and also create attractive opportunities so that people following them will look upon the vision as their own. The leaders should come to the level of the followers who have knowledge of their people's dreams, hopes and aspiration.

The third principle is to challenge the process. It focuses on the fact that the leaders should venture out to seek opportunities and accept them. The challenges may be like creating an innovative product, or to set up a new business etc. In these conditions, the leaders should create a strategy and be ready to take up risks and challenges. The leaders are early adopters of innovation. He should recognize good ideas and should challenge the system to create new products etc. Leaders are learners (Kouzes \& Posner; pg. 17). They need 
to learn from their failures and create steps towards success. This makes the people follow the leader confidently.

The fourth principle focuses on enabling others to act. Leadership is a team effort. The word "We" should be used instead of "I" (Kouzes \& Posner; pg. 17). People should be strengthened by sharing power and discretion. They must feel that they can act and be given a platform to put forth their ideas. The fifth and the last principle is to encourage the heart. The leader should make the people in the team passionate about their work. The leaders unleash their enthusiasm to the team members by narrating their success stories. They must appreciate the work done by the people and have an individual recognition.

The five principles lead to ten commitments of leadership. The principle of Model the way leads to the commitment of voicing one's views by clarifying personal values and to set the example by aligning actions with shared values. Finding one's voice is critical to becoming an authentic leader. Clarity about personal values is more important as it makes your attitude (Kouzes and Posner, 2007 page 53). By doing so the leader sets his set of values and the way in which the work will be carried out. For example the leader is particular of carrying on the work with honesty and he always stands up on his beliefs. This will help the team to conduct the work in a justified way. This will clearly set the personal and the organizational values to go hand in hand. It is the leader who makes his team competent to accept challenges and achieve the goals. This shows that leadership is a shared relationship and it is a joint effort.

The leaders with a futuristic approach keep an eye on the past incidents. This helps them to get an idea about how to model themselves and play the role of a leader effectively. For this it is necessary that the people involvement is high in decision making. This shall make them feel as a team and help in working together. A leader must also be a good listener. He should listen to their opinion and ideas carefully before making the final construct. The principle of Enable others to act have commitments that lead to fostering collaboration

\section{Utility}

The book "The Leadership Challenge" is very informative and could be beneficial to those new leaders coming up in corporate sector. The authors do a great job of familiarizing the reader with the concept of leadership challenge which is mainly focused on getting extraordinary things done in organizations and includes five practices of exemplary leadership.

The book puts forth a lot of ideas related to the human resource i.e. people. This book enlightens on how a leader can acquire the skills for him and how to behave with the people who follow him. This book helps in understanding the key aspects to build one self as a leader and to effectively make people follow that leader. I can apply these ideas and practices in a lot of situations in my personal and professional life. On the professional front, I would like to lead a team. Being a team leader I would like to develop a group of professional employees to work on the project assigned. There would be a competent group of people who would be given the freedom to put forth their ideas, opinions and have a shared vision. As a leader I would define the roles of the people based on their skill set and abilities. There would be a modeled way to let people do what they are good at. There would be a collaboration of ideas and the status quo would be challenged. The team would be motivated to take up risks and challenges and learn from the mistakes committed. Proper training can lead to efficient delivery of the results. There will be a focus on team effort and trust would be built by the word "We". The ideas would be recognized and realized. The individual contributors would be appreciated and rewarded. The rewards would be based on the needs of the people. For example if a team member needs furniture for his cabin then that would be provided as an unexpected reward.

The role of leadership is also needed in a society. For example in clubs and associations there is a club head who takes up the responsibility to conduct events and shows. If I become the head to organize an event then I would collectively engage people into various activities based on their specialization and define it accordingly. People engaged would be collaborated to present their ideas in a friendly manner and to take responsibility of the work assigned. This will lead to cooperative efforts and people will achieve desired 
results. People will be rewarded and a celebration to be conducted on successful happening of the event and also thank people who made this event a success.

\section{Conclusion}

Leadership challenge takes place in a family, society and an organization. The head of the institution or the company or the family plays the role of a leader. In order to effectively run a family, the head of the family has to model his/ her behavior in a manner which is acceptable by all. The leader should accept the thoughts of the new generation and listen attentively. The next step would be to evaluate all the ideas put forth and make a final decision. The head of the family should be passionate about the work and involve the family members to enthusiastically perform all the tasks. Looking on the other side, if I work under a manager or a team lead then I would understand the way he or she handles the team and learn from his or her behaviors. I would work as an employee to understand the key challenges to engage the team collectively in achieving the targets. This would give me a direction as to how I would lead a team with qualities such as being hard working, competent, passionate, straightforward, determined and independent. I think this book provides great insight for people/businesses man looking to find solutions for the leadership challenges they come across every day both within the organization and outside the organization.

The authors can add information about how to influence others (may be the boss). A leader will have variety of people to be lead. How to influence people at every level of the organization? These are certain important questions which remain unanswered. I would suggest the authors to include them in their forthcoming editions.

\section{References}

10 Commitments of Leadership-How to Improve Your Leadership Style. Retrieved from http://www.drexel.edu/oca/l/tipsheets/10pdf.

Kouzes, J. M., \& Posner, B. Z. (2002). The leadership challenge. San Francisco, California: Jossey-Bass.

Kouzes, James M. and Posner, Barry Z. (2007) The Leadership Challenge, Fourth edition, Jossey- Bass retrieved on 25/1/2011 from http://as.leadershipchallenge.com/WileyCDA/LCTitle/productCd0787984914.html. 